\title{
HUMAN CAPITAL INVEST AND OUTCOMES \\ (STUDI PADA TRANSFER PEMBELIAN CRISTIANO RONALDO OLEH MANAJEMEN JUVENTUS FC)
}

\author{
Oleh: \\ Bambang Septiawan,M.M. \\ Email.okbamz@gmail.com \\ Universitas Islam Balitar Blitar
}

\begin{abstract}
This research focuses on investigating the consideration of Juventus FC management for recruiting Cristiano Ronaldo related to human capital invest and outcomes context. Most of theory used in this research is about human capital invest and result or outcomes by Burud and Tumolo. It is descriptive research because it seeks to understand fenomena. The scope of this research is about financial and the subjects skills that deliver advantages for Juventus FC management. The result of this result shows that Juventus FC management consideration for investing the player are his skills, achievements, and market value. Then the outcomes are increasing Juventus stock, tickets and t-shirt sold out, attracting sponsors, and prize of the competition followed.
\end{abstract}

Key words: Human Resource Management, Human Capital, Invest and Outcomes

\section{PENDAHULUAN}

Human capital atau modal manusia memang merupakan salah satu aspek penting dalam kajian manajemen sumber daya manusia, karena seiring dengan perkembangan zaman dan tren masyarakat perusahaan yang terus berubah untuk melakukan proses manajemen sumberdaya manusia yang lebih efektif dan efisien demi mencapai sebuah tujuan organisasi. Amstrong (2009) menjelaskan jika modal manusia adalah ilmu, kecakapan, dam kemampuan seorang karyawan dalam tim atau organisasi. Lebih dari itu, Dessler (2013) menjabarkan jika human capital adalah kognitif, pendidikan, pelatian, kemampuan, dan keahlian yang dimiliki oleh pekerja perusahaan. Dapat dikatakan jika setiap karyawan memiliki bekal yang mereka bawa masing-masing dengan keunikan tersendiri yang nantinya akan mampu dimanfaatkan untuk kemajuan organisasi itu sendiri.

Karyawan dengan segala modal yang mereka miliki tentu juga akan mempertimbangkan seberapa besar kompensasi yang mereka dapatkan dari organisasi atau perusahaan. Imam (2010) membeberkan dalam jurnalnya bahwa masalah utama tentang human capital yang berhubungan dengan karyawan berkualitas adalah menjaganya sebagai aset perusahaan yang berharga, namun pasti banyak perusahaan lain yang memberi iming-iming kompensasi yang lebih besar agar mau pindah. Secara tak sadar sebetulnya akan banyak karyawan yang melakukan hal ini juga. Oleh karena itu, dibutuhkan konsep yang jitu agar organisasi ataupun perusahaan mampu memproteksi karyawannya yang berkualitas. 
Organisasi atau perusahaan pasti memiliki banyak asset yang vital, salah satunya adalah karyawan. Memiliki karyawan yang berkualiatas merupakan sebuah investasi berharga yang harus terus dikembangkan organisasi maupun perusahaan, karena baik secara langsung maupun tidak langsung akan memberi dampak yang positif bahkan mampu meningkatkan profit perusahaan tersebut. Hal ini telah dilakukan salah satu manajemen klub sepak bola terbesar di Italia yakni Juventus. Pada 10 Juli 2018 manajemen Juventus FC resmi mempekerjakan Cristiano Ronaldo sebagai pemain sepak bola mereka dengan nilai transfer 1,8 trilyun rupiah dan kontrak 2 trilyun rupiah selama 4 tahun ( CNN Indonesia, 13/7/2018).

Dana sebesar itu yang dilekuarkan oleh manejemen Juventus FC tentu sudah melalui pertimbangan yang matang, mengingat investasi pemain sepak bola sekelas Ronaldo yang memiliki banyak prestasi mulai dari pemain terbaik dunia, pemain termahal dunia, sampai pemain yang meiliki jiwa sosial tinggi tentu menjadi pertimbangan sendiri bagi manajemen tim tersebut. Ditambah lagi koleksi banyak gelar yang pernah ia raih saat membela klub sebelumya. Faktor itu semua tentu akan memberikan outcomes atau timbal balik hasil yang melebihi dari dana yang mereka keluarkan untuk mendatangkan pemain tersebut.

Uraian yang telah dijabarkan oleh penulis dapat dikonstruksikan dalam rumusan masalah yaitu, apa pertimbangan Manajemen Juventus FC dalam konteks human capital invest and outcomes saat transfer pembelian Cristiano Ronaldo untuk bergabung dengan tim mereka? Sehingga tujuan dari penulisan jurnal ini ada untuk mendeskripsikan pertimbangan Manajemen Juventus FC dalam konteks human capital invest and outcomes saat transfer pembelian Cristiano Ronaldo untuk bergabung dengan tim mereka.

Teori yang berkaitan dengan studi ini adalah Choosing to Invest in People. Burud dan Tumolo (2004) menjabarkanya dalam 5 langkah untuk memilih investasi karyawan yang tepat, sebagai berikut:

a. Indentify the Human Capital Elements in Each Type of Work

Identifikasi elemen modal manusia pada setiap jenis pekerjaan disini berfokus pada dua hal yaitu intellectual capital dan relational. Intellectual capital mengacu pada elemen keilmuan pada setiap pekerjaan. Selain itu, penerapan dari ilmu dan kemampuan karyawan dalam menciptakan mengembangkan, menggunakan, dan memperbaiki dalam setiap proses pekerjaan. Ini adalah kombinasi dari pengalaman dan pendidikan baik formal maupun informal yang bermanfaat untuk meningkatkan mutu perusahaan dalam hal produk maupun profit.

Selanjutnya relational capital merupakan kemampuan seorang karyawan untuk mejalankan hubungan baik dengan lingkungan organisasinya untuk membangun sebuah jaringan yang lebih kuat dan erat terutama dengan sektor diluar organisasi sehingga mampu mengembangkan perusahaan tersebut.

b. Understand How the Human Capital Aspects of Work Affect Result

Memahami bagaimana aspek modal manusia bekerja dan berimbas pada hasil maksudnya adalah bagaimana organisasi memutuskan bahwa modal manusia posisinya berpengaruh pada capaian organisasi. Derajat pengetahuan yang dimiliki tentu akan berakibat pada capaian organisasi, 
namun itu semua tergantung dari strategi tiap organisasi itu sendiri. Koneksi antara modal kemampuan manusia dengan kinerja organisasi sangat penting dipahami oleh manajemen. Itu akan membantu mereka untuk merekrut orang-orang yang punya kemampuan dan kapasitas untuk dikembangkan yang nantinya akan punya kontribusi besar pada organisasi.

c. Identify the Factors That Drive Human Performance

Mengidentifikasi faktor-faktor yang merangsang kinerja manusia merupakan hal penting yang harus dilakukan organisasi dengan melakukan promosi yang jelas kepada karyawannya. Kinerja umumnya berimbas pada komitmen, motivasi, dan produktifitas. Kinerja dimulai dari pemberian kerja pada talen yang tepat, karena ini wajib diketahui oleh pimpinan dan manajemen dalam suatu organisasi untuk meningkatkan kinerja karyawannya.

Faktor yang mempengaruhi kinerja tersebut adalah imbalan yang sesuai dengan kinerja, kesempatan untuk mengembangkan diri, manajemen yang mau mendengar usulan karyawan, pekerjaan yang bermakna dan sesuai dengan kemampuan, karyawan punya otonomi dan kebijakan mengenai pekerjaan yang dibebankan kepadanya, suasana pertemanan yang baik didalam dan luar organisasi, punya alat dan sumber untuk menjalankan pekerjaannya, karyawan merasa aman dengan pekerjaanya.

d. Evaluate the Workforce Profile, Needs, and Trends

Untuk merangsang human capital, seorang pemimpin dan manajemen harus mampu memahami orang-orang mereka. Tidak semua karyawan membutuhkan hal yang sama dalam organisasi agar lebih efektif dalam bekerja. Harapan dan kebutuhan karyawan dibedakan oleh jenis kelamin, umur, gaya hidup, ambisi, akhlak, dan tujuan, serta itu semua bisa saja berubah sesuai kondisi yang mereka alami.

Pada dasarnya, tidak semua organisasi memperhatikan kebutuhan orang-orang yang bekerja pada tempat mereka. Walupun demikian, akhlak, kepuasan kerja, dan keseimbangan antara kehidupan dan pekerjaan akan berefek pada kesehatan dan ketenangan meraka. Organisasi yang peka cenderung membuat keputusan untuk investasi pada karyawan, menciptakan budaya, dan mengimplementasikan secara praktis untuk memberdayakan karyawan agar terpenuhi kebutuhannya, disamping itu apa yang menjadi tujuan organisasi juga akan terwujud.

e. Recognize People as Asset, Not Expenses

Setiap pimpinan atau manajemen bahkan organisasi harus sadar jika modal manusia merupakan bagian penting dalam kesuksesan menjalankan bisnis yang mereka lakukan. Oleh karena itu, mereka harus memperlakukan orang-orang mereka sebagai aset, sebab human capital yang mumpuni pada setiap karyawan merupakan poin berharga untuk kelangsungan dan kemajuan organisasi. Jika dibandingkan, apa yang dikeluarkan organisasi atau perusahaan untuk membayar 
karyawan akan memberikan hasil yang lebih banyak bagi perusahaan maupun organisasi itu sendiri.

Kemudian ada teori yang berkaitan dengan hasil yang didapat dari investasi yang dilakukan manajemen atau perusahaan yaitu human capital resulst or outcomes. Teori tersebut dijelaskan Burud dan Tumolo (2004) sebagai berikut:

a. Creativity

Kreatifitas adalah kontribusi bagian terpenting karyawan untuk mampu membuat ide baru, kemajuan proses dan produksi. Namun kreatifitas bukanlah hal yang mudah dilakukan seperti pengucapannya. Kreatifitas karyawan dipengaruhi oleh lingkungan kerja, budaya organisasi, dukungan dari senior dan rekan kerja, tekanan dan beban kerja, tujuan yang jelas, umpan balik yang bermanfaat, dan seberapa bagus individu mengelola kesempatan dengan keahliah yang mereka miliki.

b. Commitment

Komitmen dibedakan menjadi tiga jenis. Pertama, komitmen kerja yaitu kemampuan identifikasi dan aplikasi individu pada tugas dan tanggung jawab pekerjaannya. Kedua, komitmen karir yakni seberapa penting karir dan pekerjaannya dalam hidup seseorang. Terakhir, komitmen organisasi adalah seberapa loyal individu dengan organisasi mereka.

Komitmen berbeda dengan kepuasan kerja, komitmen itu tentang kedekatan dengan organisasi itu sendiri, termasuk nilai dan tujuannya. Ketika komitmen ada, individu akan menerima tujuan dan nilai organisasi. Terlebih lagi, individu akan merasa menjadi bagian dalam satu kesatuan organisasi tersebut.

\section{c. Productivity}

Produktifitas merupakan elemen penting dalam meningkatkan profit perusahaan atau organisasi. Produktifitas muncul dari keefektivitasan yang dilakukan oleh karyawan. Secara umum, produktifitas dapat dilihat dari kuantitas dan kualitas. Kuantitas meliputi outpun yang mampu dihasilkan dengan volume pekerjaan tinggi, bekerja cepat dan akurat, dan sesuai dengan deadline. Kualitas mencakup akhlak karyawan, stamina, pelatihan, dan fokus untuk membagi ide dan ilmu demi meningkatkan produktifitas dan proses.

d. Employee Health

Kesehatan karyawan merupakan isu penting yang sering dibahas dalam modal manusia. Hal ini dapat menjadai perhatian khusus karena kesehatan sangat berharga karena dapat mengganggu produktifitas meraka dalam bekerja. Asuransi kesehatan, program yang berkualitas, kebutuhan fisik dan aspek pekerjaan lain sangat berpengaruh pada kondisi kesehatan karyawan. Perusahaan perlu melakukan strategi yang menarik untuk menjaga kesehatan karyawannya.

e. Attracting employees

Karyawan yang berkualitas dan kerasan saat bekerja dalam organisasi, tentu akan menjadi daya tarik untuk pekerja lain diluar 
organisasi. Apalagi kinerja organisasi secara umum selalu menunjukkan tren positif dan berprestasi. Perusahaan yang telah bekerja dengan peak performance harus mempertahankan kualitasnya dengan merekrut orang-orang yang memiliki kalitas caliber tinggi pula.

f. Retaining Employees

Mempertahankan karyawan dapat mengurangi biaya, meningkatkan produktifitas dan faktor penting untuk menjaga pelanggan. Karyawan lama akan tahu bagaimana selera dan keinginan konsumen daripada karyawan barunya, mereka lebih tahu apa yang dilakukan untuk organisasi. Kemahiran manajemen sangat diperlukan untuk mempertahankan meraka, manajemen harus tahu jalan yang bersahabat untuk melakukan pendekatan mulai saat mereka bekerja sampai kemampuan mereka meningkat sebagai seorang karyawan.

Penelitian ini masih berkaitan dengan beberapa studi sebelumnya. Pertama, Majewski (2016) yang meneliti tentang harga pasar pemain sepak bola ditentukan oleh jumlah gol, umpan akurat, kontribusi dalam tim dan rangking poin dalam FIFA. Kedua, Meliov (2007) mendeskripsikan jika investasi modal manusia dilakukan atas dasar usia, namun faktor lain yang harus diperhatikan adalah karyawan yang punya kemampuan dan tidak punnya kemampuan akan berpengaruh pada organisasi. Terakhir, Zink (2001) menerangkan bahwa keberadaan teknologi akan mengubah model human capital investment yang dikombinasikan dengan kemampuan berbeda yang melekat pada individu yang nantinya akan mampu menjelaskan tentang fenomena labor market.

\section{MOTODOLOGI PENELITIAN}

Penelitian ini menggunakan pendekatan kualitatif, karena menganalisa tentang pemahaman fenomena tentang pertimbangan manejemen Juventus FC pada tranfer pembelian Ronaldo dalam konteks human capital invest and outcomes. Penelitian ini juga termasuk deskriptif karena berisikan tentang penjelasan dan penjabaran detail tentang pertimbangan manejemen Juventus FC pada tranfer pembelian Ronaldo dalam konteks human capital invest and outcomes.

Subjek atau informan dalam penelitian ini adalah manajemen Juventus FC dalam proses perekrutan Ronaldo, karena diindikasikan manajemen tersebut menerapkan konsep human capital invest and outcomes. Mengingat status Ronaldo sebagai pemain terbaik sepakbola dunia dan durasi kontrak empat tahun yang disetujui.

Sumber data dalam penelitian ini adalah press release dari manejemen Juventus FC, melalui website resmi juventus.com/en serta web berita olah raga terpercaya seperti cnnindonesia.com, okezone.com bola.com, dan lainnya. Sedangkan data berbentuk laporan berita secara deskriptif yang menjabarkan proses transfer Ronaldo ke Juventus FC dari berbagai sumber media online tersebut. Instrument utama dalam penelitian ini adalah peneliti sendiri. Peneliti sendiri yang akan menentukan proses pengambilan data sampai ke analisis data.

Teknik pengumpulan data dalam penelitian ini dibagi dalam beberapa tahap. Pertama, peneliti mencari berita tentang perpindahan atau pembelian Ronaldo dari Real Madrid FC ke Juventus FC. Kedua, Peneliti mengklasifikasikan 
berita-berita atau press release yang berhubungan dengan human capital invest and outcomes. Ketiga, peneliti membaca dan mengambil data tentang pertimbangan manajemen Juventus FC dari berita-berita tersebut. Terakhir, peneliti menentukan data yang diindikasikan memuat pertimbangan manajemen Juventus FC secara human capital invest and outcomes dalam membeli Ronaldo.

Teknik analisa dalam penelitian ini ada beberapa tahap. Pertama, data dibagi dalam kategori investasi atau hasil dari modal manusia dari proses pembelian Ronaldo oleh manajemen Juventus FC. Kedua, data tersebut dikategorikan berdasarkan teori dari Burud dan Tumolo (2004) tentang invest dan outcomes pada modal manusia. Ketiga, dilakukan intepretasi data untuk mencari pertimbangan (alasan) dari manajemen Juventus FC dalam pembelian Ronaldo dengan konteks human capital invest dan outcomes. Lebih jauh lagi, dari seluruh data yang dianalisa, dapat ditarik kesimpulan mengenai masalah penelitian. Penarikan kesimpulan merupakan bagian akhir dari hasil penelitian.

Cakupan dan batasan dalam penelitian ini adalah pertimbangan manajemen Juventus FC untuk membeli Ronaldo dari segi keuntungan keuangan dan non teknis secara umum dari kacamata modal manusia secara investasi dan hasil yang didapat berdasarkan kalkulasi analisa dana sederhana dari berita atau press release yang ada dalam media masa. Kemudian diintegrasikan dengan kapasital human capital yang dimiliki oleh Ronaldo sebagai pemain terbaik dunia lima kali. Penelitian ini tidak membahas proses negosiasi secara detail anatara pemain dengan klub dan antar klub hingga proses pananda tanganan kontrak. Terakhir, triangulasi tidak dibuat karena keterbatasan waktu penelitian.

\section{HASIL DAN PEMBAHASAN}

Berdasarkan penelitian yang dilakukan dapat diformulasikan hasil dari segi human capital invest dan outcomes yang menjadi pertimbangan manajemen Juventus FC untuk merekrut Ronaldo sebagai berikut:

Pertimbangan dari segi investasi, pertama dari Indentify the Human Capital Elements in Each Type of Work. Sudah bukan menjadi rahasia umum jika Ronaldo merupakan pemain dengan skill luar biasa. Hal itu dia buktikan dengan meraih gelar pemain terbaik Eropa sebanyak lima kali, top skor liga champion eropa 8 kali dan la liga 3 kali, serta masih banyak yang lain (goal.com 10 Juli 2018). Selain itu jiwa sosial ronaldo yang tinggi tentu akan menjadi daya tarik lebih bagi manajemen. Contohnya ketika dia tidak mentato tubuhnya dengan alasan sering mendonorkan darahnya (bola.com 4 April 2018). Selain itu Ronaldo mengangkat anak korban tsunami aceh bernama Martunis dan mengabulkan pemintaannya (kompas.com 6 Desember 2018). Faktor itulah yang mendukung klub manapun tidak hanya Juventus FC dan klub lain rela untuk merekrutnya.

Kedua, Understand How the Human Capital Aspects of Work Affect Result ini dibuktikan dengan apa yang dimiliki Ronaldo secara modal akan mampu mendorong timya untuk meraih ambisi juara Liga Champion, Liga Italia, Super copa dan Copa Italia (kompas.com 14 Agustus 2018). Pengalaman yang dimiliki Ronaldo saat membela klub sebelumnya tentu akan sangat berimbas pada mental dan permainan dalam tim untuk meraih itu semua. Ditambah dengan usianya yang sudah matang akan menambah mental yang mumpuni untuk menghadapi laga 
besar. Tentu jika itu semua terwujud pundi-pundi keuntungan yang didapatkan oleh manjemen Juventus FC akan meningkat.

Ketiga, Identify the Factors That Drive Human Performance merupakan hal yang dipertimbangkan oleh manajemen Juventus FC juga. Gaji sebesar 41,8 milyar rupiah perbulan yang merupakan gaji terbesar dalam sepak bola Itali 2018 (goal.com 4 September 2018). Gaji tersebut bisa dibilang tiga kali lipat dibandingkan dengan pemain lainnya. Belum ditambah bonus yang dia terima dan pendapatan lain diluar klub. Tentu faktor itu semua akan menambah kinerjanya sebagai pemain andalan yang mampu merubah hasil akhir dalam suatu pertandingan.

Keempat, Evaluate the Workforce Profile, Needs, and Trends juga telah dilakukan oleh manjemen. Ronaldo merupakan pemain yang komplit, dia merupakan pemain dengan skill yang mumpuni untuk mencetak goal dari kondisi open play maupun bola mati. Selain itu, sosoknya yang tampan dan muda merupakan sebuah nilai plus dari apa yang dibutuhkan para penggemar untuk menarik meraka agar terus datang ke stadion. Ronaldo juga merupakan tren pusat anak muda dalam berkarir maupun bergaya didalam dan luar lapangan.

Terakhir, Recognize People as Asset, Not Expenses. Secara fakta membuktikan jika manajemen Juventus FC harus mengeluarkan dana lebih untuk membeli Ronaldo. Tapi itu semua meraka anggap sebagai aset yang sangat berharga demi meraih keuntungan besar. Bisa dipastikan tim ini akan menjadi magnet dunia dengan hadirnya Ronaldo. Sudah tentu apa yang mereka keluarkan akan berubah menjadi profit besar dengan adanya Ronaldo di tim ini minimal dengan durasi 4 tahun kontrak yang disepakati.

Lebih dari itu, outcomes of human capital dari pembelian Ronaldo oleh manejemen Juventus FC dapat dijabarkan pertama, dari sisi kreatifitas dan komitmen. Ronaldo ingin selau bermain meski usianya sudah menginjak 33 tahun, seperti yang diungkapkan pelatihnya. Ini menandakan jika ia masih memiliki stamina yang prima dan membawa manfaat untuk membantu timnya menang dan ini menunjukkan kominmen kuat yang ia miliki untuk membela tim. Kemudian, dari sisi kreatifitas dia sudah menymbang 14 gol dan 5 assist, yang merupakan separuh jumlah gol yang telah dihasilkan timnya selain rekor lain yang dia pecahkan untuk Juventus FC (detik.com 25 Noember 2018).

Kedua, dari segi produktifitas masalah keuangan Ronaldo menyumbang banyak keuntungan untuk timnya. Tiket pertandingan 2018-2019 ludes terjual, terbukti $95 \%$ pemegang tiket sebelumnya telah memperbaharui tiket mereka. Serta sisanya dijual ke anggota klub dengan harga tingggi mencapai 30\% kenaikan. Selanjutnya, jersey atau kaos Ronaldo terjual 915 milyar dalam 24 jam atau sekitar 520.00 buah sehari. Lebih dari itu, harga saham Juventus FC naik 10-20\% per tiga hari yang tentunya akaan meningkatkan keuangan tim dan manajemen. Jumlah pengikut media sosial Juventus FC naik secara pesat. Tentu saja ini akan membawa banyak sponsor yang berdatangan (okezone.com 25 Juli 2018).

Ketiga, tentang kesehatan pemain. Sudah tidak diragukan lagi dengan profesionalisme manajemen tim Juventus FC dan didukung program latihan mumpuni akan membuat kondisi Ronaldo tetap bugar. Terbukti dengan banyak gol yang dia ciptakan. Selain itu gaya hidup Ronaldo yang sehat akan mendukung 
kebugaran fisiknya sehingga minim cedera. Secara tidak langsung itu semua akan mebuat keuntungan besar dengan sering tampilnya Ronaldo bersama timnya.

Terakhir, untuk loyalitas dan pengaruh Ronaldo akan memiliki magnet yang kuat untuk menarik pemain lain datang dan bergabung dengan manajemen Juventus FC. Itu semua terjadi karena tim yang dibela Ronaldo pasti memiliki target tinggi sebagai juara. Selain itu, pemain lain terutama pamain muda juga akan banyak yang berdatangan untuk menimba ilmu denganya. Dampaknya akademi juve junior pun juga akan semakin banya peminat.

Dari hasil yang telah dikemukan, penelitian ini sejalan dengan apa yang Majewski (2016) tulis dalam jurnalnya, jika harga pemain seperti Ronaldo akan tetap tinggi jika kemampuan untuk mencetak golnya tinggi serta banyaknya penghargaan yang telah diraihnya. Tetapi penelitian ini tidak sejalan dengan yang diungkapkan Meliov (2007) yang menjelaskan investasi manusia didasarkan pada usia. Dalam kasus ini meskipun usia Ronaldo sudah mendekati 34 tahun namun kinerjanya dalam tim masih prima, karena dia merpuakan pemain yang displin untuk menjaga fisiknya. kemudian Zink (2001) punya ide yang sejalan dengan penelitian ini, jika peran teknologi sangat besar dalam proses human capital invest terbukti dengan datangya Ronaldo media sosial Juventus FC kebanjiran Follower. Ini sangat berdampak positif bagi manejemen untuk mengaet sponsor yang ingin bekerjasama dengan tim ini.

\section{KESIMPULAN DAN SARAN}

Dari penelitian yang telah dijabarkan dapat disimpulkan bahwa pertimbangan yang dilakukan manajemen Juventus FC dalam transfer pembelian Ronaldo dalam konteks human capital invest and outcomes adalah kapasitasnya sebagai pemain yang sangat berkualitas, market value Ronaldo yang tinggi, dan imbal balik keuntungan yang tinggi mulai dari naiknya saham, tiket, kaos, sponsor, sampai hadiah kompetisi yang dimenangkan tim.

Saran dalam penelitian ini yaitu peneliti selanjutnya diharapkan untuk melakukan triangulasi data dengan ahli atau subjek maupun objek terkait untuk lebih mendukung keabsahan data penelitian. Akan lebih baik jika ada perbandingan data dengan keputusan dan pertimbangan pembelaian pemain lain yang masih dalam satu manajemen.

\section{DAFTAR PUSTAKA}

Al Umam, Hanief Syafi. 2018. Efek Ronaldo, Ambisi Juventus Raih Liga Champions Meningkat. Diunduh pada www.bola.kompas.com diakses pada $14 / 8 / 2018$

Amstrong, Micahael. 2009. Human Resource Management Practice. London and Philadelphia: Kogan Page

Burud, Sandra L. and Marie Tumolo. 2004. Leveraging Human Capital: adaptive strategies, result achieved, and stories of transformation. Mountain view USA: Davies-Black Publishing

Dessler, Gary. 2013. Human Resource Management. New Jersey: Pearson Education 
Majewski, Sebastian. 2016. Identification of Factors Determining Market Value of the Most Valuable Football Player. Journal of Management and Business Administration. Central Europe. Vol.24 No.3 Page 91-104

Nuralam, Cakrayuri. 2018. 4 Hal Menarik dari C.Ronaldo Selain Gol Salto. Diunduh pada www.m.bola.com Diakses pada 4/12/2018

Press Release Juventus. Agreement with Real Madrid for the Definitive Acquisition of the Player Cristioano Ronaldo. 2018. Diunduh pada Juventus.com/en diaksen pada 10/7/2018

Rachman, Rivan Nasri. 2018. 4 Keuntungan Juventus Datangkan Ronaldo, Nomor 2 Paling Terasa. Diunduh pada www.bola.okezone.com Diakses pada 25/7/2018

Ronaldo Catatan Prestasi Menuju Juventus. Diunduh pada www.goal.com diakses pada $10 / 7 / 2018$

Salehudin, Imam. 2010. INVEST IN YOURSELF: Aplikasi Konsep Human Capital dari Sudut Pandang Karyawan. Jurnal Manajemen Usahawan Indonesia. No. 06/TH. XXXIX 2010. ISSN: 0302-9859

Salusi, Novitasari Dewe. 2018. Ada Ronaldo dalam Separuh Gol Juventusdi Liga Italia Sejauh ini. Diunduh pada www.detik.com/sepakbola diakses pada $25 / 11 / 2018$

Terungkap Gaji Mewah Ronaldo di Juventus. Diunduh pada www.goal.com Diakses pada 4/9/2018

Veliov, Vladimir M. and Alexia Prskawetz. 2007. Age-Specific Dynamic Labor Demand and Human Capital Investement. Journal of Economic Dynamic and Control. Vol. 31 3741-3777

Wibowo, Haryanto Tri. 2018. Gaji Ronaldo di Juventus. Diunduh pada www.ccindonesia.com Diakses pada 13/7/2018

Wicaksono, Windi. 2018. Juventus Raup Keuntungan Besar Berkat Pembelian Ronaldo. Diunduh pada www.bola.com Diakses pada 19/7/ 2018

Wirajati, Jalu Wisnu. 2017. Cerita Ronaldo Kabulkan 3 Permintaan Martunis. Diunduh pada www.bola.kompas.com diakses pada 4/12/2018

Zink, Stefan and Jurgen Meck1. 2001. Human Capital Investement and the Wage Gap. Economic Theory. University Konstanz. Vol. 19 853-859 